\title{
Pharmacokinetic Activity of Quercetin in Rats Following Single Dose Intramuscular Administration
}

\author{
Falguni D. Modi ${ }^{1 *}$, S.K. Bhavsar ${ }^{2}$, J.H. Patel ${ }^{1}$, R.D. Varia $^{1}$, L.C. Modi ${ }^{3}$ and \\ Megha Modi ${ }^{1}$
}

${ }^{1}$ Department of Veterinary Pharmacology and Toxicology, ${ }^{2}$ Department of Veterinary Pharmacology and Toxicology, ${ }^{3}$ Department of Veterinary Gynecology, College of Veterinary Sci. \& A.H, Navsari Agricultural University, Navsari, Gujarat, India

*Corresponding author

\section{A B S T R A C T}

\section{Keywords \\ Pharmacokinetic, Quercetin, Rat \\ Article Info \\ Accepted: \\ 12 September 2018 \\ Available Online: \\ 10 October 2018}

Pharmacokinetic activity of Quercetin $(100 \mathrm{mg} / \mathrm{kg})$ was studied following intramuscular administration in rats. Drug concentration in rat plasma was determined using High Performance Liquid Chromatography (HPLC) following intramuscular administration of Quercetin $(100 \mathrm{mg} / \mathrm{kg})$ in rats. The pharmacokinetic parameters like the mean peak (Cmax) plasma drug concentration, time taken to reach the maximum concentration (Tmax), elimination half-life $\left(\mathrm{t}_{1 / 2 \beta}\right)$, total body clearance $\left(\mathrm{Cl}_{(\mathrm{B})}\right)$ and mean residence time (MRT) were $0.96 \pm 0.18 \mu \mathrm{g} / \mathrm{mL}, 0.25 \pm 0.02 \mathrm{~h}, 0.25 \pm 0.03 \mathrm{~h}, 356.53 \pm 36.63 \mathrm{~L} / \mathrm{h} / \mathrm{kg}$ and $0.43 \pm 0.04 \mathrm{~h}$, respectively were determined.

\section{Introduction}

Polyphenolic compounds, especially flavonoids, are known as the most common chemical class of phytochemicals, which possess various biological and pharmacological activities.

Among various flavonoids, Quercetin (3, 3', 4', 5, 7-pentahydroxyflavone) has a unique biological elements having health benefits. It is a plant pigment, commonly found in vegetables and fruits in the form of a glycoside. It is categorized as a flavonol, one of the six subclasses of flavonoid compounds. It is known to have antioxidant (Ozgen et al., 2016), anti-inflammatory (Abbey and Rankin, 2011), anti-carcinogenic (Fresco et al., 2010), neuroprotective (Sasaki et al., 2003), antibacterial (Cushnie and Lamb, 2005) and antiviral (Gatto et al., 2002) properties. Most of pharmacokinetic studies of Quercetin have been conducted following oral and intravenous route but in veterinary clinical medicine intramuscular route is most preferred route of administration in domestic animals. 
Hence, pharmacokinetic of Quercetin by intramuscular route was conducted in rats.

\section{Materials and Methods}

\section{Experimental animals}

The experiment was conducted on male Albino wistar rats weighing between 300 to 400 grams. Rats were kept under constant observation for two weeks before the commencement of the experiment and subjected to clinical examination to exclude possibility of any diseases. The animals were divided into groups and kept in cages. Standard ration and water was provided ad libitum. The experimental protocol was approved by Institutional Animal Ethics Committee.

\section{Drug and chemical}

Pure Quercetin hydrate was obtained from Sigma-Aldrich, St. Louis, USA. Dimethysulfoxide (DMSO), PEG200, Methanol, Acetonitrile, Glacial acetic acid and Normal Saline (NS) were purchased from Merck Specialities Private Limited, Mumbai. Ethanol was used from store of College of Veterinary Science and A.H., N.A.U., Navsari after triple distillation.

\section{Pharmacokinetic study and data analysis}

Animals $(\mathrm{n}=30)$ were divided into six groups. Each group comprise of five animals. Multiple numbers of rats were used for serial collection of blood at alternating time points. A single dose of Quercetin was given by intramuscular route in each group of animal at dose rate 100 $\mathrm{mg} / \mathrm{kg}$ B.W. Blood samples $(250 \mu \mathrm{L})$ were collected from treated rat in K3EDTA vials, at different time interval i.e., 0 (before drug administration), 0.08 (5 min), 0.25 (15 min), 0.5 (30 min), 1, 2, 4, 6, 8, 12, 18 and 24 hours from retro orbital plexus under light anesthesia. Blood samples were subjected to centrifugation at $5000 \mathrm{rpm}$ for 10 minutes to separate plasma. Plasma samples were transferred to cryo-vials and then stored at $20^{\circ} \mathrm{C}$. Samples were analyzed within $24-48 \mathrm{~h}$ to quantify Quercetin levels using High Performance Liquid Chromatography (HPLC). Quercetin was assayed in rat plasma by adopting procedure with minor modifications (Ang et al., 2014). The High Performance Liquid Chromatography (HPLC) apparatus of Shimadzu (Japan) comprised of binary gradient delivery pump (model LC - 20AP), Diode Array Detector (model SPD M20A), Auto Sampler (model SIL 20A) and reverse phase C18 column ( $250 \times 4.6 \mathrm{~mm}$ ID). For the precipitation of the plasma protein, Acetonitrile and Glacial acetic acid mixture (9:1 ratio) was added in plasma as 1:1 ratio were mixed in a clean microcentrifuge tube on a vortex mixer for 1 minute. It was followed by centrifugation for 15 minutes at $8000 \mathrm{rpm}$. The clean supernatant was transferred into inserts (automatic sampler vial) from which 20 $\mu \mathrm{L}$ of supernatant was injected into HPLC system. The mobile phase consisted of a mixture of $2 \%$ glacial acetic acid and ACN $(60: 40 \mathrm{v} / \mathrm{v}), \mathrm{pH} 4.0$. Mobile phase was filtered by $0.2 \mu$ size filter (Axiva N66) and degassed by ultra-sonication. The mobile phase was pumped into column at a flow rate of 1.0 $\mathrm{mL} / \mathrm{min}$ at ambient temperature. The effluent was monitored at $370 \mathrm{~nm}$ wavelength. Various pharmacokinetic parameters were calculated from plasma concentration of Quercetin using software PK solution (Version 2.0). For validation of HPLC method, initial stock solution of Quercetin was prepared by dissolving $2 \mathrm{mg}$ pure Quercetin in $2 \mathrm{~mL}$ DMSO, PEG200, Ethanol and Normal Saline in 3:3:2:2 ratio. Final standards were prepared in drug-free rat plasma. The mean correlation coefficient $\left(\mathrm{R}^{2}\right)$ was 0.99 for calibration curves. The Precision and accuracy of the assay were assessed using samples at concentration of $12.50,1.563,0.391$ and 0.098 
$\mu \mathrm{g} / \mathrm{mL}$. At all concentration studied, the C.V. of Quercetin was less than $3.18 \%$.

\section{Statistical analysis}

Quercetin plasma concentration and pharmacokinetic parameters of different treatment groups were compared by students' " $t$ " test using Microsoft excel 2007.

\section{Results and Discussion}

Quercetin levels of plasma as a function of time schedule after its single intramuscular administration $(100 \mathrm{mg} / \mathrm{kg}$.) in rats is depicted in table 1 , while semilogarithmic plots of the same have been presented in figure 1 . Following intramuscular administration of Quercetin, the drug concentration of $0.14 \pm 0.03 \mathrm{mg} / \mathrm{mL}$ was observed at $0.08 \mathrm{~h}$. The mean peak plasma drug concentration of $0.96 \pm 0.18 \mathrm{mg} / \mathrm{mL}$ was achieved at $0.25 \mathrm{~h}$ which declined rapidly to $0.09 \pm 0.02 \mathrm{mg} / \mathrm{mL}$ at $0.5 \mathrm{~h}$. The drug concentration of $0.07 \pm 0.01$ $\mathrm{mg} / \mathrm{mL}$ in plasma was detected at $1 \mathrm{~h}$ and beyond then the drug was not detected in plasma. Contrary to the present observation low peak drug concentration of $0.61 \mu \mathrm{g} / \mathrm{mL}$ (Khaled et al., 2003), $0.09 \mu \mathrm{g} / \mathrm{mL}$ (Erlund et al., 2000), $0.29 \pm 0.06 \mu \mathrm{g} / \mathrm{mL}$ (Dong et al., 2017) and $0.63 \pm 0.06 \mu \mathrm{g} / \mathrm{mL}$ (Lv et al., 2017) has been reported following oral administration in rats. Whereas, higher plasma levels of $1.97 \pm 0.41 \mu \mathrm{g} / \mathrm{mL}$ (Luo et al., 2016) and $1.13 \pm 0.33 \mu \mathrm{g} / \mathrm{mL}$ (Yang et al., 2013) in rats and $2.12 \pm 1.63 \mu \mathrm{g} / \mathrm{mL}$ (Graefe et al., 2001) in humans have been reported following oral administration.

The elimination half-life $\left(\mathrm{t}_{1 / 2 \beta}: 0.25 \pm 0.03 \mathrm{~h}\right)$ of Quercetin in rats following single dose intramuscular administration in present study was found lower than reported following intravenous administration as $1.85 \mathrm{~h}$ (Khaled et al., 2003) and $3.84 \mathrm{~h}$ (Tang et al., 2009) in rats, $1.92 \pm 0.62 \mathrm{~h}$ in rabbit (Liu et al., 2011) and $3.72 \mathrm{~h}$ in dogs (Wu et al., 2012). Whereas, very longer elimination half-life of $36.45 \pm$ $14.08 \mathrm{~h}$ (Yang et al., 2013), $17.70 \pm 3.70 \mathrm{~h}$ (Erlund et al., 2000) and $13.60 \pm 14.09 \mathrm{~h}$ in rats (Dong et al., 2017) and $11.90 \pm 4.00 \mathrm{~h}$ in human (Graefe et al., 2001)has been reported following oral administration. The apparent volume of distribution $\left(\mathrm{Vd}_{(\mathrm{area})}\right)$ 132.92 \pm 24.14 $\mathrm{L} / \mathrm{kg}$ ) of Quercetin following single dose intramuscular administration in rats was found very higher than found $1.16 \mathrm{~L} / \mathrm{kg}$ in rats (Khaled et al., 2003) and $21.63 \mathrm{~L} / \mathrm{kg}$ in dogs (Wu et al., 2012) following intravenous administration. Whereas, very low apparent volume of distribution of $14.96 \pm 4.44 \mathrm{~L} / \mathrm{kg}$ (Luo et al., 2016) and $71.70 \mathrm{~L} / \mathrm{kg}$ (Khaled et al., 2003) in rats following oral administration have been reported.

Fig.1 Semilogarithmic plot of quercetin concentration in plasma versus time following single dose intramuscular administration of quercetin $(100 \mathrm{mg} / \mathrm{kg})$ in rats.

\section{Each points represents mean \pm S.E.}

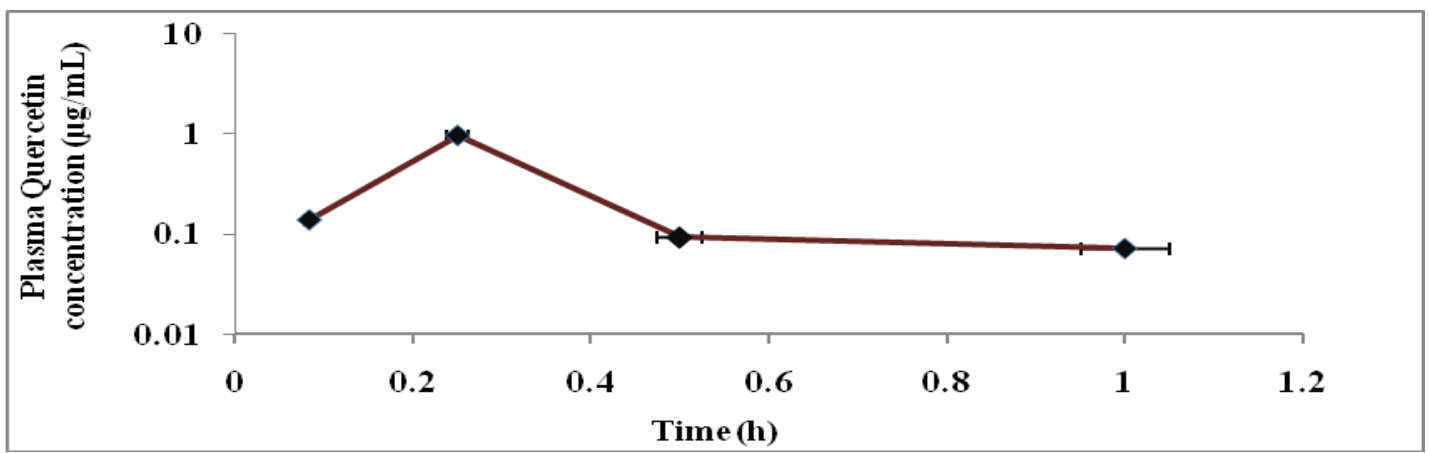


Table.1 Pharmacokinetic parameters of quercetin $(100 \mathrm{mg} / \mathrm{kg})$ following intramuscular administration in rats

\begin{tabular}{|c|c|c|c|c|c|c|c|c|}
\hline \multirow{2}{*}{$\begin{array}{l}\text { Pharmacokinetic } \\
\text { Parameter }\end{array}$} & \multicolumn{7}{|c|}{ Rat Number } & \multirow[t]{2}{*}{ Mean \pm S.E } \\
\hline & Unit & R1 & $\mathbf{R} 2$ & $\mathbf{R 3}$ & R4 & R5 & R6 & \\
\hline $\bar{\alpha}$ & $\mathrm{h}^{-1}$ & 4.87 & 3.32 & 4.98 & 6.74 & 5.59 & 10.32 & $5.97 \pm 0.98$ \\
\hline$\beta$ & $\mathrm{h}^{-1}$ & 3.46 & 2.49 & 3.50 & 3.14 & 2.97 & 1.85 & $2.90 \pm 0.26$ \\
\hline$t_{1 / 2 a}$ & $\mathrm{~h}$ & 0.142 & 0.209 & 0.139 & 0.103 & 0.124 & 0.067 & $0.13 \pm 0.01$ \\
\hline$\overline{t_{1 / 2 \beta}}$ & $\mathrm{h}$ & 0.20 & 0.28 & 0.20 & 0.22 & 0.23 & 0.37 & $0.25 \pm 0.03$ \\
\hline $\mathbf{C}_{\max }$ & $\mu \mathrm{g} / \mathrm{mL}$ & 1.05 & 0.60 & 1.64 & 0.99 & 1.10 & 0.40 & $0.96 \pm 0.18$ \\
\hline $\mathbf{T}_{\max }$ & $\mathrm{h}$ & 0.24 & 0.35 & 0.24 & 0.21 & 0.24 & 0.20 & $0.25 \pm 0.02$ \\
\hline $\mathbf{A U C}_{(0-\infty)}$ & $\mu \mathrm{g} . \mathrm{h} / \mathrm{mL}$ & 0.30 & 0.20 & 0.45 & 0.26 & 0.32 & 0.25 & $0.30 \pm 0.03$ \\
\hline AUMC & $\mu \mathrm{g} \cdot \mathrm{h}^{2} / \mathrm{mL}$ & 0.11 & 0.10 & 0.16 & 0.09 & 0.13 & 0.16 & $0.12 \pm 0.01$ \\
\hline $\mathbf{V} \mathbf{d}_{\text {(area) }}$ & $\mathrm{L} / \mathrm{kg}$ & 95.28 & 195.98 & 63.86 & 123.45 & 105.56 & 213.40 & $132.92 \pm 24.14$ \\
\hline $\mathbf{C l}_{(\mathbf{B})}$ & $\mathrm{L} / \mathrm{h} / \mathrm{kg}$ & 329.53 & 488.88 & 223.50 & 387.62 & 314.02 & 395.62 & $356.53 \pm 36.63$ \\
\hline MRT & $\mathbf{h}$ & 0.37 & 0.50 & 0.35 & 0.35 & 0.39 & 0.62 & $0.43 \pm 0.04$ \\
\hline
\end{tabular}

In the present study, the total body clearance $\left(\mathrm{Cl}_{(\mathrm{B})}: 356.53 \pm 36.63 \mathrm{~L} / \mathrm{h} / \mathrm{kg}\right)$ of Quercetin was in conflict with reported value of clearance very low body clearance of $2.95 \mathrm{~L} / \mathrm{h} / \mathrm{kg}$ (Khaled et al., 2003) and $9.94 \mathrm{~L} / \mathrm{h} / \mathrm{kg}$ (Tang et al., 2009) in rats, $2.03 \pm 0.22 \mathrm{~L} / \mathrm{h} / \mathrm{kg}$ in rabbits (Liu et al., 2011) and $4.03 \mathrm{~L} / \mathrm{h} / \mathrm{kg}$ in dogs (Wu et al., 2012) following intravenous administration has been reported. Similarly lower body clearance of $0.01 \mathrm{~L} / \mathrm{h} / \mathrm{kg}$ (Khaled et al., 2003) and $1.85 \pm 0.53$ $\mathrm{L} / \mathrm{h} / \mathrm{kg}$ (Luo et al., 2016) has been observed in rats following oral administration. However, The MRT values calculated following single dose intramuscular administration of Quercetin in present study was $0.43 \pm 0.04 \mathrm{~h}$ in rats. It is in agreement with the MRT of $0.39 \mathrm{~h}$ (Khaled et al., 2003) and 0.56h (Tang et al., 2009) reported in rats following intravenous administration of Quercetin. Contrary to the present observation, very high MRT of $11.90 \pm 5.40 \mathrm{~h}$ in human (Graefe et al., 2001), 8.64 \pm 1.64 h (Luo et al.,

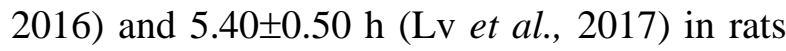
have been reported following oral administration.

\section{Acknowledgement}

The facility and infrastructure provided by Dean, College of Veterinary science and A. H.,
Navsari to conduct this study is duly acknowledged.

\section{Conflict of interest statement}

Authors declare that they have no conflict of interest.

\section{References}

Abbey, E.L. and Rankin, J.W. 2011. Effect of Quercetin supplementation on repeated sprint performance, xanthine oxidase activity, and inflammation. Int J Sport Nutr Exerc Metab., 91(6).

Ang, L.F., Yam, M.F., Fung, Y.T.T., Kiang, P.K. and Darwin, Y. 2014.HPLC method for simultaneous quantitative detection of Quercetin and Curcuminoids in traditional Chinese medicines. $J$ Pharmaco puncture., 17(4):36-49.

Cushnie, T.P. and Lamb, A.J. 2005. Antimicrobial activity of flavonoids. Int $J$ Antimicrob Agents, 26:343-56.

Dong, X., Lan, W., Yin, X., Yang, C., Wang, W. and Ni, J. 2017. Simultaneous determination and pharmacokinetic study of Quercetin, Luteolin and Apigenin in rat plasma after oral administration of Matricaria Chamomilla extract by HPLC- 
UV. Evidence-Based Complementary and Alternative Medicine, 1-7.

Erlund, I., Kosonen, T., Alfthan, G., Maenpaa, J., Perttunen, K., Kenraali, J., Parantainen, J. and Aro, A. (2000). Pharmacokinetics of quercetin from quercetinaglycone and rutin in healthy volunteers. Eur J Clin Pharmacol, 56: 545-553.

Fresco, P., Borges, F., Marques, M. and Diniz, C. (2010). The anticancer properties of dietary polyphenols and its relation with apoptosis. Curr Pharm Des, 16:114-34.

Gatto, M.T., Falcocchio, S. and Grippa, E. (2002). Antimicrobial and anti-lipase activity of quercetin and its $\mathrm{C}_{2}-\mathrm{C}_{16} 3-\mathrm{O}$ acyl esters. Bioorg Med Chem, 10: 26972.

Graefe, E.U., Wittig, J., Mueller, S., Riethling, A., Uehleke, B., Drewelow, B., Pforte, H., Jacobasch, G., Derendorf, H.and Veit, M. (2001). Pharmacokinetics and bioavailability of Quercetin glycosides in humans. Journal of Clinical Pharmacology, 41: 492-499.

Khaled, K.A., El-Sayed, Y.M.andAl-Hadiya, B.M. (2003). Disposition of the flavonoid Quercetin in rats after single intravenous and oral doses. Drug Dev. Ind. Pharm., 29: 397-403.

Liu, X., Tang, D., Wu, J. and Yin, X. (2011).Gradient

HPLC-DAD

Determination and pharmacokinetic study of Ginkgo biloba extract in rabbits. Lat. Am. J. Pharm., 30(3): 507-13.

Luo, X, Yang, T., Yang, C., Zhou, J., Liu, Y., Huang, Y.and Shi, S (2016). Effects of multiple oral dosing of cyclosporine on the pharmacokinetics of Quercetin in rats. Int J Clin Exp Med., 9(3): 5880-5890.

Lv, L., Liu, C., Li, Z., Song, F., Li, G.and Huang, X. (2017). Pharmacokinetics of Quercetin-loaded methoxy poly (ethylene glycol)-b-poly (l-lactic acid) micelle after oral administration in rats. Bio Med Research International Volume, 1- 7.

Ozgen, S., Kilinc, O.and Selamoglu, Z. (2016). Antioxidant Activity of Quercetin: A Mechanistic Review. Turkish Journal of Agriculture - Food Science and Technology, 4(12): 1134-1138.

Sasaki, N., Toda, T.and Matsuo, M. (2003). Protective effects of flavonoids on the cytotoxicity of linoleic acid hydroperoxide toward rat pheochromocytoma PC12 cells. Chem Bio Interact., 145: 101-16.

Tang, D., Yin, X., Zhang, Z., Gao, Y., Wei, Y., Chen, Y.and Han, L. (2009). Comparative Study on the pharmacokinetics of Ginkgo biloba extract between normal and diabetic rats by HPLC-DAD. Lat. Am. J. Pharm., 28 (3): 400-8.

Wu, J., Xing, H., Tang, D., Gao, Y., Yin, X., Du, Q., Jiang, X.and Yang, D. (2012). Simultaneous determination of nine flavonoids in beagle dog by HPLC with DAD and application of Ginkgo biloba Extracts on the pharmacokinetic. Acta Chromato graphica, 24(4): 627-642.

Yang, Z., Cao, X., Wei, Y., Zhang, W., Zhao, M.and Duan, J. (2013). Pharmacokinetic study of rutin and quercetin in rats after oral administration of total flavones of mulberry leaf extract. Rev Bras Farmacogn., 23:776-782.

\section{How to cite this article:}

Falguni D. Modi, S.K. Bhavsar, J.H. Patel, R.D. Varia, L.C. Modi and Megha Modi. 2018. Pharmacokinetic Activity of Quercetin in Rats Following Single Dose Intramuscular Administration. Int.J.Curr.Microbiol.App.Sci. 7(10): 1562-1566. doi: https://doi.org/10.20546/ijcmas.2018.710.175 